\title{
Suppression of Crystallization in Ti-Based Alloys by Fluxing
}

\author{
Ichiro Seki ${ }^{1}$, Dmitri V. Louzguine-Luzgin ${ }^{2}$, Toshitugu Takahashi ${ }^{1}$, \\ Hisamichi Kimura ${ }^{1}$ and Akihisa Inoue ${ }^{1,2}$ \\ ${ }^{1}$ Institute for Materials Research, Tohoku University, Sendai 980-8577, Japan \\ ${ }^{2}$ WPI Advanced Institute for Materials Research, Tohoku University, Sendai 980-8577, Japan
}

Controlling crystal nucleation and growth leading to formation of nano structures by an original flux treatment method mainly in calcia and magnesia crucibles followed by water-cooling allowed production of $\mathrm{Ti}_{45} \mathrm{Cu}_{45} \mathrm{Fe}_{10}$ bulky nanostructured alloy of $16 \mathrm{~mm}$ in diameter. Since a glass forming ability (GFA) of the alloy composition is low, the alloy could not form an amorphous structure even by a common rapid quenching manner such as a melt-spun method. At the same time control over crystal nucleation and growth by fluxing was achieved on melting with fluxa reagent which has a low melting temperature and good wettability. The crystal growth control in our investigations is also possible for different other alloys such as $\mathrm{Ti}_{45} \mathrm{Cu}_{45} \mathrm{Ni}_{10}$ alloy. [doi:10.2320/matertrans.MBW201001]

(Received August 10, 2010; Accepted October 6, 2010; Published November 24, 2010)

Keywords: titanium alloy, calcium deoxidation, metallic glass, nano crystalline, nucleation

\section{Introduction}

Although amorphous alloys (which include also nano structured alloys) have characteristic and fantastic mechanical and chemical properties and are produced by selecting of alloy composition with large negative enthalpy, and large different atomic size, high cooling-rates are required to fabricate the amorphous alloys. ${ }^{1)}$ Especially, high coolingrate is important factor to produce the amorphous structure, for suppression of crystal growth and heterogeneous nucleation. Although homogeneous nucleation is possible, it is rarely observed compared to heterogeneous nucleation. Heterogeneous nucleation commonly takes place at impurity inclusion, i.e., titanium has a high affinity with oxygen, which is dissolved in $\mathrm{Ti}$ and also forms oxides after solidification. Therefore, reported titanium-based amorphous alloys (metallic glass) commonly have a small size up to $10 \mathrm{~mm},{ }^{2-6)}$ and it is considered that the production of large size bulk amorphous alloys is difficult because the crystal growth is easily caused by heterogeneous nucleation. As one of available removal manners of the nucleation site, fluxing technique is known and utilized for Fe-, Pd- and Pt-based metallic glasses which are commonly treated with $\mathrm{B}_{2} \mathrm{O}_{3} \cdot{ }^{7-14}$ ) However, since $\mathrm{B}_{2} \mathrm{O}_{3}$ is reduced by molten metals with high oxygen affinities such as titanium, the common fluxing technique can be applied only for low oxygen affinity metals such as Fe-, Pd-, and Pt-based metals. Therefore, it is necessary to discover new available flux compositions. The present author's group tried to discover new flux compositions to control the nucleus made of oxide, and applied it to titanium based alloys.

Two kinds of alloys compositions of $\mathrm{Ti}_{45} \mathrm{Cu}_{45} \mathrm{Fe}_{10}$ and $\mathrm{Ti}_{45} \mathrm{Cu}_{45} \mathrm{Ni}_{10}$ have been selected in the present work. The alloy compositions are based on equal content of titanium and copper and an addition of a third alloying element. Although the alloy compositions are decided from simplification of the compositions, critical sample size of $\mathrm{Ti}_{50} \mathrm{Cu}_{42.5} \mathrm{Ni}_{7.5}$ metallic glass alloy similar to one of the selected alloy composition has been reported to be less than
$0.2 \mathrm{~mm}$ in thickness. ${ }^{3)}$ Since the reported critical size is small, influence of difference of fabrication methods can be tested.

$\mathrm{CaO}$-based flux with low melting temperature was used as a basic element. Phase relation (diagram) of $\mathrm{CaO}-\mathrm{CaCl}_{2}$ flux was investigated by many researchers. ${ }^{15-17)}$ The thermodynamic properties were also investigated. ${ }^{17-19)}$ In addition, the $\mathrm{CaO}-\mathrm{CaCl}_{2}$ flux was utilized in deoxidation processes of pure titanium, ${ }^{20-23)}$ and they succeeded in decreasing of oxygen content in solid titanium by a solid state diffusion of oxygen at $1273 \mathrm{~K}^{21)}$ Since the $\mathrm{CaO}-\mathrm{CaCl}_{2}$ flux system has eutectic point of $1023 \mathrm{~K}$ at $6.5 \mathrm{~mol} \% \mathrm{CaO}$ and the temperature is lower than the liquidus line of $1226 \mathrm{~K}$ for titanium metallic glass composition of $\mathrm{Ti}_{50} \mathrm{Cu}_{42.5} \mathrm{Ni}_{7.5}{ }^{3)}$ whose composition is similar to the alloys in the present work, the flux is also available for processing of the selected titanium-based alloys. In the present work, to clarify the possibility of smelting with the flux for the $\mathrm{Ti}_{45} \mathrm{Cu}_{45} \mathrm{Fe}_{10}$ and $\mathrm{Ti}_{45} \mathrm{Cu}_{45} \mathrm{Ni}_{10}$ alloys, optimum (available) compositions of flux based on the $\mathrm{CaO}$ $\mathrm{CaCl}_{2}$ flux have been selected.

\section{Experimental Procedure}

Flux compositions were based on $\mathrm{CaO}-\mathrm{CaCl}_{2}$ system, in which phase diagram was already reported. ${ }^{15-17)}$ The flux was melted in $\mathrm{CaO}$ crucible, and that of composition was fixed as a function of temperature dependent on phase rule as shown by the following function;

$$
f=C-P+T=2-2+1=1
$$

In the function, $f$ means freedom, $C$ is component $\left(\mathrm{CaO}+\mathrm{CaCl}_{2}\right), P$ is phase $(\mathrm{CaO}$ cru. + Liq. $+(\mathrm{CaO}+$ Liq.)) and $T$ means function of temperature and is shown by " 1 ". The flux was heated from 1173 to $1573 \mathrm{~K}$ in the $\mathrm{CaO}$ crucible, and the composition was saturated (equilibrated) with almost $20 \mathrm{~mol} \%$ of $\mathrm{CaO}$ from the phase diagram. In addition, $\mathrm{MgO}$ was added into the flux to control other physico-chemical properties of flux such as constituent's activity, viscosity and wettability. Since it is known that $\mathrm{MgO}$ and $\mathrm{CaO}$ have unlimited solid solubility, ${ }^{24)}$ it is suggested 


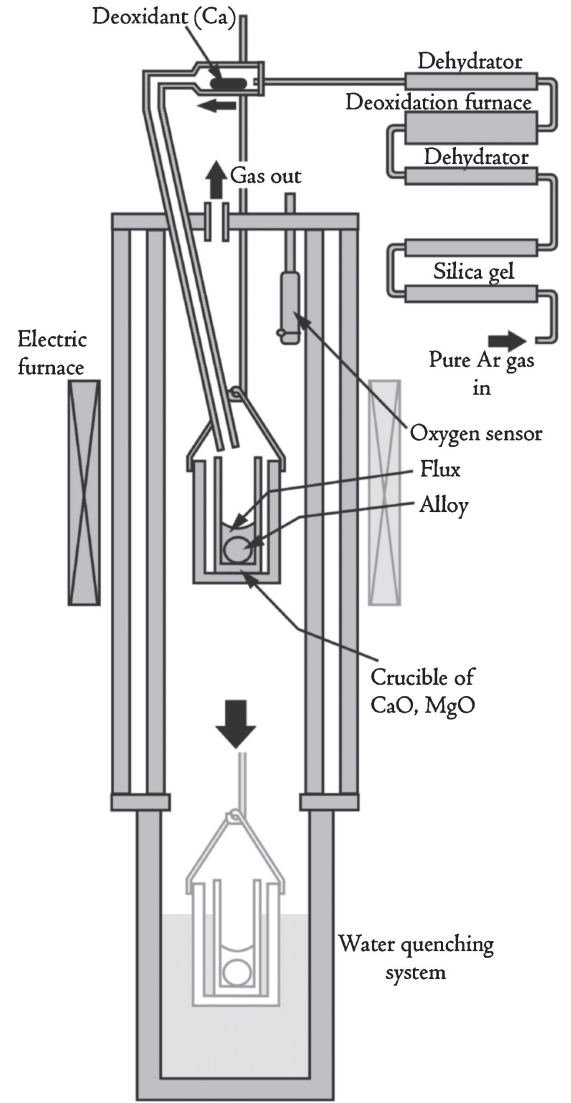

Fig. 1 Schematic diagram of the electric resistance furnace.

that the activity of the flux can be controlled by changing $\mathrm{CaO} / \mathrm{MgO}$ ratio without large phase relation change. The flux was prepared from mixtures of high purity $\mathrm{CaCO}_{3}, \mathrm{MgO}$ and $\mathrm{CaCl}_{2} \cdot 2 \mathrm{H}_{2} \mathrm{O}$ powders $\left(\mathrm{Al}_{2} \mathrm{O}_{3}\right.$ was also added into the mixture to control the flux properties in some cases), and was melted together with titanium-based alloys in $\mathrm{CaO}$ or $\mathrm{MgO}$ crucible with a vertical electric resistance furnace. Compositions of the alloys were $\mathrm{Ti}_{45} \mathrm{Cu}_{45} \mathrm{Fe}_{10}$ and $\mathrm{Ti}_{45} \mathrm{Cu}_{45} \mathrm{Ni}_{10}$, which were referred to common titanium-based metallic glass compositions. ${ }^{2-6)}$ The alloys were prepared by arcmelting in an Ar atmosphere.

The vertical electrical resistance furnace utilized in the smelting of the alloys is schematically shown in Fig. 1. Detailed descriptions were given in a previous paper. ${ }^{25)} \mathrm{An}$ atmosphere in the furnace was kept with an Ar gas flow of $2 \mathrm{Nml} / \mathrm{s}$. When the experimental temperature was kept at $1473 \mathrm{~K}$, the oxygen partial pressure in the atmosphere gas was $3.3 \times 10^{-36}$ atom at measuring temperature of $843 \mathrm{~K}$ which was located above the crucible as shown in Fig. 1. The alloys and the mixtures of the flux compositions were melted in the crucible after a vacuum suction and the gas purge for $1200 \mathrm{~s}$ in the bottom of the tube. Weight of the alloys was 5 to $19 \mathrm{~g}$, and that of the mixtures of flux was 2 to $5 \mathrm{~g}$. The melted alloys and mixtures were kept at various experimental temperatures for $1800 \mathrm{~s}$. Continuously, calcium-block of 0.05 to $0.5 \mathrm{~g}$ as deoxidant was added into the melts. Since the equilibrating time exceeded $3600 \mathrm{~s}$ in the previous study, ${ }^{25}$ ) the melts were kept for various times of 5400 to $7200 \mathrm{~s}$. The melts were quenched into a water-pool which was located in bottom place. Cooling rate of the melts could be estimated at about $20-30 \mathrm{Ks}^{-1}$ by visual observation of an emission color change from 1473 to $773 \mathrm{~K}$. The quenched alloys were cut to several parts as shown in Fig. 2(a). Atomic structure on the cutting surface of middle place for the quenched alloys was investigated with $\mathrm{X}$-ray diffractometry using $\mathrm{CuK} \alpha$ radiation, and the measurement conditions such as several slit sizes and $\mathrm{X}$-ray power were not changed in the present work. The largest bulk alloy with only broad peaks from XRD investigation was also investigated to confirm the existence of amorphous phase by transmission electron microscopy (TEM). Oxygen content for the prepared alloy was measured by LECO TC-436 (LECO Corp.) which employs an infrared absorption method.

\section{Results}

Figure 2(a) shows the polished cross section of the water-cooled $\mathrm{Ti}_{45} \mathrm{Cu}_{45} \mathrm{Fe}_{10}$ alloy after the smelting with $\left(\mathrm{CaO}_{0.1} \mathrm{MgO}_{0.9}\right)_{20}\left(\mathrm{CaCl}_{2}\right)_{80}$ flux in the $\mathrm{MgO}$ crucible at $1458 \mathrm{~K}$. Although the alloy surface is covered with an oxide layer such as large block located in right side in Fig. 2(a), the middle section of the alloy shows metallic luster. The diameter of the sample after grinding of the oxidized layer was about $16 \mathrm{~mm}$. The quenched alloys were also covered by the flux film on the oxide layer. Although the oxygen content which was reached to $1900 \mathrm{ppm}$ was shown by the chemical analysis for the sample, contamination by flux could not be observed macroscopically. Figure 2(b)-(c) shows bright and dark field images and (d) a high resolution TEM image along with typical selected area electron diffraction (SAED) patterns as Fig. 2(c), (e), (f) of the sample, and its diffraction patterns show TEM rings and stacking diffraction images. These diffraction patterns represent formation of nano structure and submicron-size structure, are suggesting that the fluxing technique could influence the nucleation and growth rate effectively.

Figure 3 shows the XRD profiles of the quenched $\mathrm{Ti}_{45} \mathrm{Cu}_{45} \mathrm{Fe}_{10}$ alloy with various flux compositions in the $\mathrm{MgO}$ crucibles at various temperatures. Figure 3(a)-(d) presents the influence of smelting temperature dependence, and Fig. 3(b), (e) compares flux composition dependence, respectively. The diameter of the smelted samples in Fig. 3(a), (c)-(e) was $11 \mathrm{~mm}$, while it was $16 \mathrm{~mm}$ in case of Fig. 3(b). For the investigation of capable suppression condition for the crystallization at solidification, the experiment was started from the $\mathrm{CaO}-\mathrm{CaCl}_{2}$ flux without $\mathrm{MgO}$ addition, and added $\mathrm{MgO}$ step by step into the flux to compare the effect of the suppression at fixed temperature of $1473 \mathrm{~K}$. Flux composition of around $10 / 90_{(\mathrm{CaO} / \mathrm{MgO})}$ was shown with good suppression behavior than other ratios of the flux, for the crystallization at the temperature. Next, capable temperature for the suppression of crystallization is investigated by the changing of temperature step by step, and was determined as around $1458 \mathrm{~K}$ as shown by Fig. 3(b). Since it is speculated that upon the smelting condition of (b) is possible to control the nucleation and crystal growth significantly compared with the production of other smelted samples in various conditions, we tried to manufacture the larger alloy sample. From the comparison of the XRD profiles, sharp peaks related to crystallization were observed 

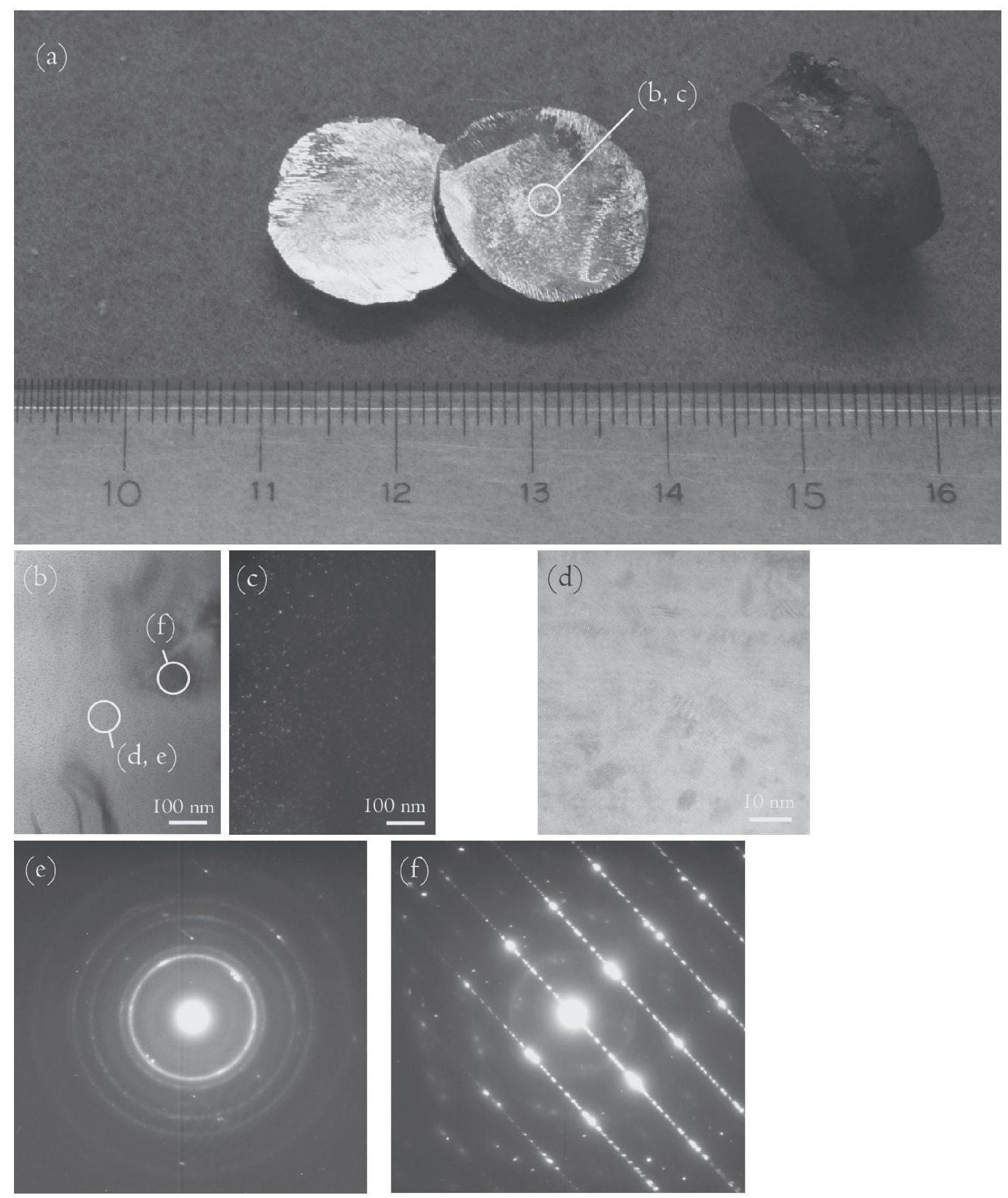

Fig. 2 (a) Outer surface of smelted $\mathrm{Ti}_{45} \mathrm{Cu}_{45} \mathrm{Fe}_{10}$ alloy with $10 / 90_{(\mathrm{CaO} / \mathrm{MgO})}$ flux at $1458 \mathrm{~K}$. (b)-(c) Bright and dark field images and (d) HRTEM image along with (e)-(f) typical SAED patterns of the sample (a).

in the smelted alloys of (a), (d). On the other hand, the sharp peaks become broadened significantly in the alloys of (c), and seem almost to disappear in the alloys of (b). This behavior means the sharp peaks with crystallization appear with the changing to upper or lower temperatures from the capable temperature of $1458 \mathrm{~K}$. Similarly, flux composition dependence at fixed temperature is also observed as difference of XRD profiles as shown by Fig. 3(b), (e), and 10/90 (CaO/MgO) seems to be effective composition in the present study for the suppression of crystallization.

In Fig. 4, (a), (b) show the XRD profiles of original alloys of the $\mathrm{Ti}_{45} \mathrm{Cu}_{45} \mathrm{Fe}_{10}$. The two kinds of the alloys are prepared to compare the influence of nucleation site for the crystal growth behavior, i.e., much nuclei of oxide are included in the ingot of (a) because the pre-melted alloy is covered with oxide layer (scale), and the nuclei in the ingot of (b) are decreased as much as possible because the scale is removed by mechanical grinding compared with the preparing state. The alloy prepared with the arc-melting formed large crystals. On the other hand, the crystal size in the alloy upon the rapid cooling becomes smaller. Figure 4(c), (d) show the XRD profiles of the $\mathrm{Ti}_{45} \mathrm{Cu}_{45} \mathrm{Ni}_{10}$ alloy, and their difference is compared without and with $\mathrm{Al}_{2} \mathrm{O}_{3}$ addition ( $3 \%$ for flux weight) to $\left(\mathrm{CaO}_{0.1} \mathrm{MgO}_{0.9}\right)_{20}\left(\mathrm{CaCl}_{2}\right)_{80}$ flux in $\mathrm{Al}_{2} \mathrm{O}_{3}$ crucible at $1223 \mathrm{~K}$. The crystallization of the smelted alloy was controlled effectively.

\section{Discussion}

Flux treatment controls the crystal growth in the $\mathrm{Ti}_{45} \mathrm{Cu}_{45} \mathrm{Fe}_{10}$ and $\mathrm{Ti}_{45} \mathrm{Cu}_{45} \mathrm{Ni}_{10}$ alloys. Especially, since the broad XRD peaks are observed in $\mathrm{Ti}_{45} \mathrm{Cu}_{45} \mathrm{Fe}_{10}$, it can be concluded that the crystal growth in the $\mathrm{Ti}_{45} \mathrm{Cu}_{45} \mathrm{Fe}_{10}$ alloy is suppressed, leading to nanostructure. 

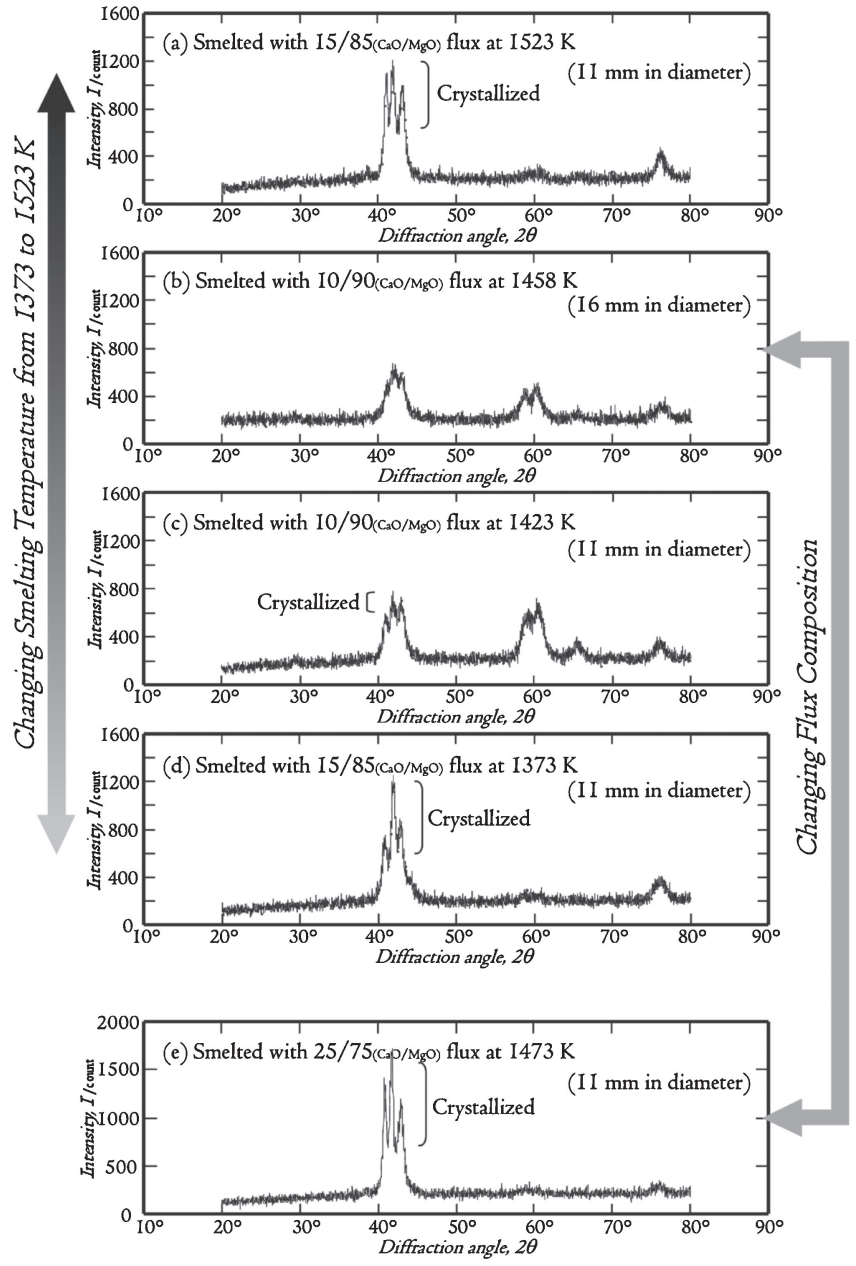

Fig. 3 XRD profiles of cutting surfaces of middle sections of $\mathrm{Ti}_{45} \mathrm{Cu}_{45} \mathrm{Fe}_{10}$ alloys smelted with various flux compositions at various temperatures.

Figure 5(a), (b) illustrate images of crystal growth controlling mechanism at the solidification process of the melts. (a) represents common case of the nucleation and crystal growth, and (b) illustrates the flux-treated case. In the common case shown by Fig. 5(a), nucleation is caused by titanium-based oxides as a substrate. Since the oxides have high melting temperature, crystal growth starts easily from the oxides by heterogeneous nucleation, like on the epitaxial crystal growth process. On the other hand, as shown in Fig. 5(b), since the oxides are equilibrated to flux which has unstable structure, the nucleation is not caused easily compared with the common case of epitaxial process.

In the present work, the effect of various processing conditions such as flux composition and temperatures has been investigated to clarify the available flux conditions to control the nucleus structure. The sharp XRD peaks related to crystalline phase become broader with changing the flux compositions and temperatures, as shown by the XRD profiles in Fig. 3. One of the important points is that the sharp peaks become weaker by selecting specific flux composition and temperature. Wide smelting conditions such as the flux composition of between $0 / 100_{(\mathrm{CaO} / \mathrm{MgO})}$ and $100 / 0_{(\mathrm{CaO} / \mathrm{MgO})}$ and temperature range from 1473 to $773 \mathrm{~K}$ have been used in the present study. The crystal growth-controlled $\mathrm{Ti}_{45} \mathrm{Cu}_{45} \mathrm{Fe}_{10}$ alloy was formed only from the flux compo-
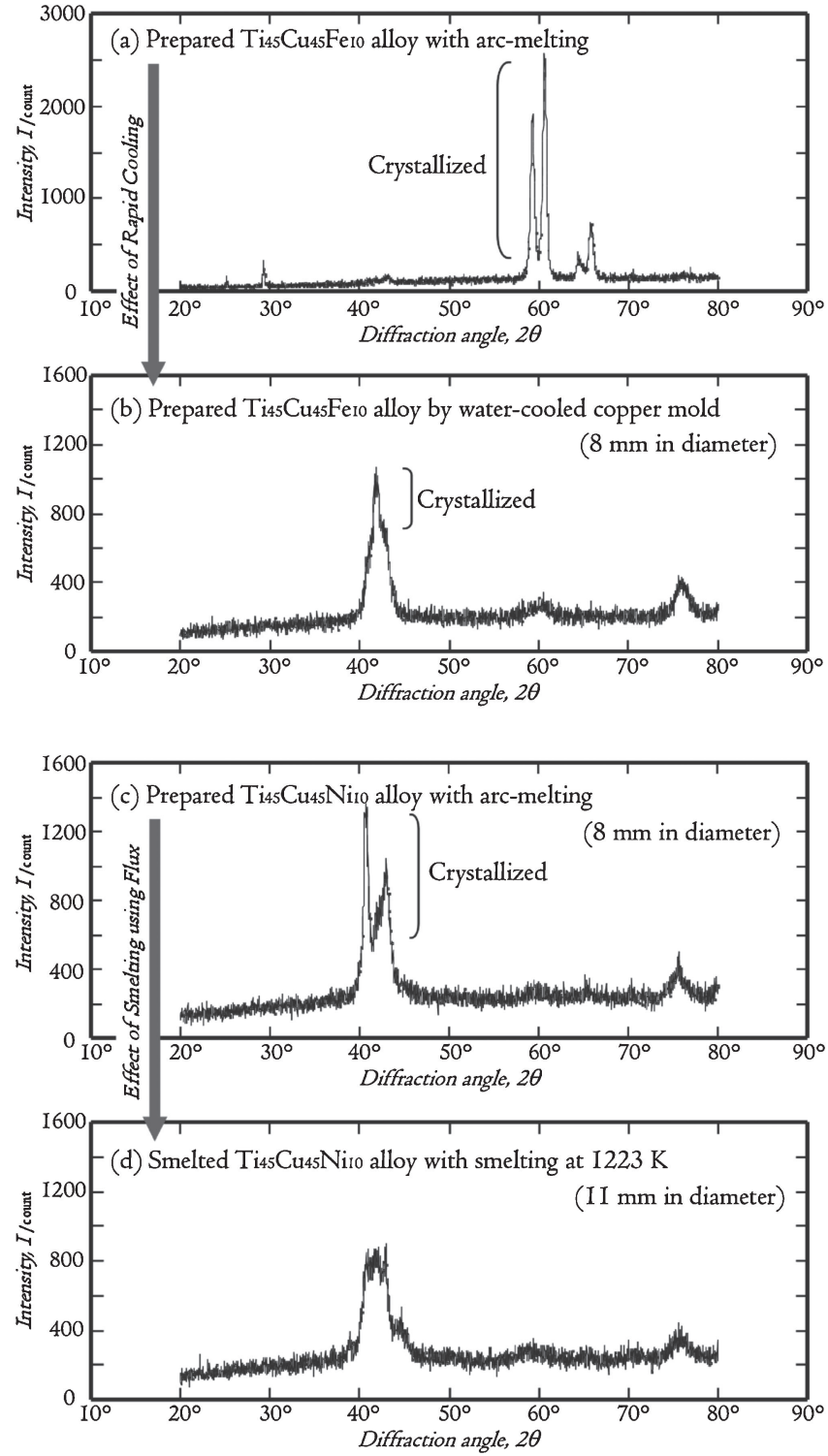

Fig. 4 XRD profiles of the prepared original alloy of $\mathrm{Ti}_{45} \mathrm{Cu}_{45} \mathrm{Fe}_{10}$ (a), (b) and $\mathrm{Ti}_{45} \mathrm{Cu}_{45} \mathrm{Ni}_{10}$ (c), (d). (a) is prepared by arc-melting, (b), (c) are prepared using the water cooled copper mold, and (d) is the smelted alloy with flux at $1223 \mathrm{~K}$.

sition of $10 / 90_{(\mathrm{CaO} / \mathrm{MgO})}$ and temperature range of $1458 \mathrm{~K}$. Similarly, the crystal growth-controlled $\mathrm{Ti}_{45} \mathrm{Cu}_{45} \mathrm{Ni}_{10}$ alloy was also formed with the $\mathrm{Al}_{2} \mathrm{O}_{3}$-added flux of $10 / 90_{(\mathrm{CaO} / \mathrm{MgO})}$ at $1223 \mathrm{~K}$. Since the shape of the XRD profiles related to the formation of crystalline phase was changed linearly and gradually with changing the flux composition and temperature from the present investigations, it was possible to decide specific composition of the flux and temperature. However, one needs to decide the specific composition and temperature range for the alloys.

It is known that the changes of the flux composition and the temperature are related to those of oxide activity (oxides in the flux), viscosity and wettability between the oxides and the alloys. The oxide activity is controlled with the flux composition. The oxygen content in the melts is controlled thermodynamically and hence, it is possible to control the nucleation process. Similar effect is shown in Fig. 4(a), (b), 


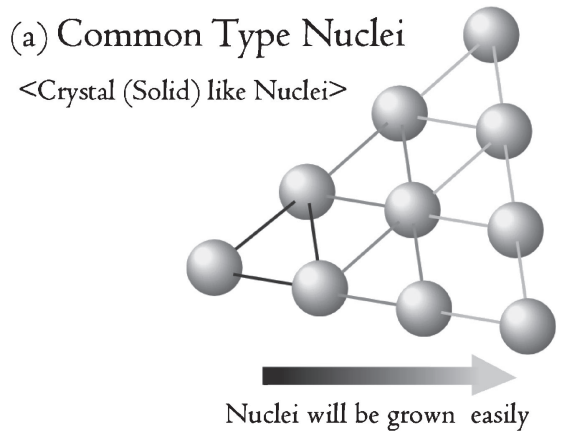

(b) Controlled Nuclei with Flux $<$ Liquid like Nuclei> (Nuclei melted with flux)

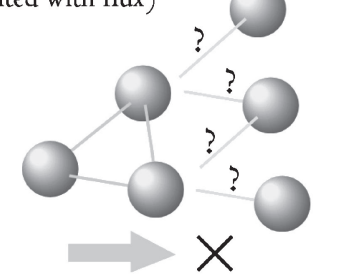

Atoms can not find stable Site before Freezing

Fig. 5 Illustration of the crystal growth image of the alloys at freezing. (a) shows the image of the common case, and means the crystal growth occurs from nucleus with epitaxial growth. On the other hand, (b) shows the case of fluxing and means the crystal growth does not progress easily because the nucleus has not stable structure like as crystalline.

and the crystal size and nucleation site in the alloy prepared with water-cooled copper mold of (b) are smaller and fewer than that of the alloy with arc-melting of (a). It can be suggested that the difference in the crystal growth behavior is influenced with the quantitative difference in nucleation sites with removing of oxides or not from the alloy before the melting.

Rate of the crystal nucleation and growth depends on supersaturation ratio $^{26)}$ which is relating with Gibbs free energies of the nucleation and the crystal growth as their driving force. Since the crystal growth in the melted titaniumbased alloy starts from the heterogeneous nucleation sites, the rate of crystal growth depends on the interfacial energy between the nuclei and the melt such as molecular size and dimension of the structure.

On the other hand, the heterogeneous crystal nucleation and growth depend on oxide content statistically. Since oxygen content of the flux-treated alloys did not decrease significantly compared to the original alloy, one can consider only removal of the oxide inclusions except for dissolved oxygen, or can consider remaining of the oxide inclusions which equilibrate to flux. Also, the excessive dissolved oxygen causes precipitation of the inclusion at cooling process. Control of the viscosity and wettability of the flux by selecting the flux composition becomes important factors. Since the viscosity and wettability depend on temperature, these physico-chemical properties of flux can be controlled by selecting the smelting temperature. The viscosity influences reactivity and is decreased with increasing temperature. On the other hand, it is commonly known the viscosity changes also with changing of composition for $\mathrm{SiO}_{2}$-included flux such as $\mathrm{CaO}-\mathrm{SiO}_{2}$ system utilized for ironmaking. Since the composition change of the $\mathrm{SiO}_{2}$-included flux is accompanied with basicity change, which is expressed by $\mathrm{CaO} / \mathrm{SiO}_{2}$ and causes activity change of oxygen in the flux, ${ }^{27)}$ the viscosity is also influenced significantly ${ }^{28)}$ by structural change such as network structure. However, the basicity is kept whether the composition changes the $\mathrm{CaO} /$ $\mathrm{MgO}$ ratio in case of the present study, and the viscosity change can not be expected. Therefore, it is plausible the effective manner to changing viscosity is the control of the smelting temperature.

When alloys are smelted at the highest or lowest temperatures, the crystal growth is not controlled enough from the investigation in the present trials as shown in Fig. 3(a)-(d). The viscosity (which becomes small at high temperature and is effective for smelting accompanied with reactivity of deoxidation) and the wettability (which becomes poor at low temperature and is effective for saving of the heterogeneous nucleation) behave like function of temperature. Therefore, it is speculated that the crystal growth is controlled capably at middle range temperature of $1458 \mathrm{~K}$ as shown in Fig. 3(b). Since the oxygen content in smelted alloy is $1900 \mathrm{ppm}$ which is higher than the original alloy of $600 \mathrm{ppm}$, the efficiency of the smelting with flux is expected to control the nucleus structure rather than quantitative decrease of the nucleus.

\section{Conclusion}

Controlling of crystal nucleation and growth leads to formation of nano structures by an original smelting method with flux, followed by water-cooling $\mathrm{Ti}_{45} \mathrm{Cu}_{45} \mathrm{Fe}_{10}$ bulky alloy of $16 \mathrm{~mm}$ in diameter. The crystal growth control in our investigations is also possible for different other alloys such as $\mathrm{Ti}_{45} \mathrm{Cu}_{45} \mathrm{Ni}_{10}$ alloy.

\section{Acknowledgement}

This work was financially supported in part by Grant-inAid for Young Scientists (B) No. 19760457 from Japan Society for the Promotion of Science (JSPS) and by Research and Development project on Advanced Metallic glasses, Inorganic Materials and Joining Technology (Advanced Materials Development and Integration of Novel Structured Metallic and Inorganic Materials) from The Ministry of Education, Culture, Sports, Science and Technology (MEXT) of Japan. Much advice for manufacture technique of experimental equipment was given much advice from Professor Mitsutaka Hino (Hokkaido Polytechnic College Independent Administrative Organization Employment and Human Resources Development Organization of Japan/ Professor Emeritus, Tohoku University).

\section{REFERENCES}

1) A. Inoue: Acta Mater. 48 (2000) 279-306.

2) X. H. Lin and W. L. Johnson: J. Appl. Phys. 78 (1995) 6514-6519.

3) C. Ma, H. Soejima, S. Ishihara, K. Amiya, N. Nishiyama and A. Inoue: Mater. Trans. 45 (2004) 3223-3227.

4) H. Men, S. Pang, A. Inoue and T. Zhang: Mater. Trans. 46 (2005) 2218-2220. 
5) X. Guo, D. Louzguine and A. Inoue: Mater. Trans. 42 (2001) 24062409.

6) I. Seki, H. Kimura and A. Inoue: J. Phys. Conference Series 144 (2009) 012003.

7) T. D. Shen and R. B. Schwarz: Appl. Phys. Lett. 75 (1999) 49-51.

8) H. W. Kui, A. L. Greer and D. Turnbull: Appl. Phys. Lett. 45 (1984) 615-616.

9) Y. He, R. B. Schwarz and J. I. Archuleta: Appl. Phys. Lett. 69 (1996) 1861-1863.

10) A. Inoue and N. Nishiyama: Mater. Sci. Eng. A 266-228 (1997) 401-405.

11) N. Nishiyama and A. Inoue: Mater. Trans. JIM 38 (1997) 464-472.

12) N. Chen, D. Pan, D. V. Louzguine, G. Q. Xie, M. W. Chen and A. Inoue: Scr. Mater. 62 (2010) 17-20.

13) K. Takenaka, T. Wada, N. Nishiyama, H. Kimura and A. Inoue: Mater. Trans. 46 (2005) 1720-1724.

14) N. Nishiyama, K. Takenaka, T. Wada, H. Kimura and A. Inoue: Mater. Trans. 46 (2005) 2807-2810.

15) W. D. Threadgill: J. Electrochem. Soc. 112 (1965) 632-633.

16) D. A. Wenz, I. Johnson and R. D. Wolson: J. Chem. Eng. Data 14 (1969) 250-252.

17) S. Wang, F. Zhang, X. Liu and L. Zhang: Thermochem. Acta 470
(2008) 105-107.

18) Y. Tago, Y. Endo, K. Morita, F. Tsukihashi and N. Sano: ISIJ Int. 35 (1995) 127-131.

19) Y. Morioka, K. Morita, F. Tsukihashi and N. Sano: Tetsu to Hagané 81 (1995) 40-45.

20) K. Ono, T. Okabe, M. Ogawa and R. Suzuki: Tetsu to Hagané 76 (1990) 568-575.

21) T. H. Okabe, R. O. Suzuki, T. Oishi and K. Ono: Tetsu to Hagané 77 (1991) 93-99.

22) R. O. Suzuki and S. Fukui: Mater. Trans. 45 (2004) 1665-1671.

23) K. Kobayashi, Y. Oka and R. O. Suzuki: Mater. Trans. 50 (2009) 2704-2708.

24) W. J. M. Van der Kemp, J. G. Blok, P. R. Van der Linde, H. A. J. Oonk, A. Schuijff and M. L. Verdonk: CALPHAD: Comput. Coupling Phase Diagrams Thermochem. 18 (1994) 255-267.

25) I. Seki, T. Ashino, J. Tanabe and K. Nagata: Steel Res. Int. to be submitted.

26) M. J. McNallan, M. J. Yurek and J. F. Elliott: Combustion and Flame 42 (1981) 45-60.

27) T. Yokokawa and K. Niwa: Mater. Trans. JIM 10 (1969) 81-84.

28) M. J. Toplis and D. B. Dingwell: Geochim. Cosmochim. Acta 68 (2004) 5169-5188. 